\title{
Relationship Between Adoption and Suicide Attempts: A Meta-analysis
}

\author{
Adalberto Campo-Arias (iD ${ }^{1,}{ }^{*}$, Jorge Armando Egurrola-Pedraza (iD ${ }^{1}$ and Edwin Herazo (iD ${ }^{2}$ \\ ${ }^{1}$ Faculty of Health Sciences, University of Magdalena, Santa Marta, Colombia \\ ${ }^{2}$ Human Behavioral Research Institute, Bogotá, Colombia \\ "Corresponding author: Medicine Program, Faculty of Health Science, University of Magdalena, Carrera 32 No 22-08, Santa Marta, (Código postal 470004), Colombia. Email: \\ acampoa@unimagdalena.edu.co
}

Received 2020 June 29; Revised 2020 August 19; Accepted 2020 August 22.

\begin{abstract}
Context: Several investigations have shown that people in an adoption situation have a higher frequency of mental problems or disorders than the general population. However, no known meta-analysis consolidates information about the association between the adoption situation and suicide attempt.

objectives: We aimed to systematically evaluate the primary observational studies that quantified the association between the being adopted and suicide attempt.

Methods: A systematic review was designed that used a logical strategy based on specific descriptors in Spanish, English, and Portuguese, in combination with the Boolean operators (AND, OR). The search was performed on the following databases: PubMed, Scopus, Health Virtual Library, ProQuest, EBSCOhost, PsycArticles, BioMed Central, and Sage Journal. Articles were included until December 2018. The quality of the studies was evaluated with a tool based on the STROBE criteria.

Results: Six studies met the inclusion criteria. Three studies used case-control designs and the remaining three were cohort studies. Case-control studies computed 69 suicide attempts in 1,216 adopted people compared to 436 attempts amidst 20,555 non-adopted people $\left(\mathrm{OR}=2.30,95 \% \mathrm{CI} 1.24-4.28, \mathrm{I}^{2}=61 \%\right)$. Cohort studies computed 536 suicide attempts among 36,965 people in adoption compared to 15,112 attempts in 3,118,069 non-adopted people $\left(\mathrm{RR}=2.99,95 \% \mathrm{CI} 2.54-3.53, \mathrm{I}^{2}=73 \%\right)$.

Conclusions: The adoption situation can increase suicide attempts; it predicts at least two times more cases of suicide attempts among adopted people than in the general population.
\end{abstract}

Keywords: Adoption, Suicide, Risk Factors, Meta-analysis

\section{Context}

Adoption is the voluntary acceptance of a child of other parents as one's child, usually with a legal confirmation. Adoption, whether formal or informal, has always been a method of ensuring the survival of children whose parents are unwilling or unable to care for them (1). An adoptive family can provide a supportive environment for recovering from physical and psychological injuries and reversing some developmental deficits (2). However, adoption can also profoundly affect child development. Adopted people have a higher lifetime prevalence of psychological distress or mental disorders. This higher risk of psychiatric problems in this population may be explained by the conjugation of both genetic and environmental factors (3).

On the other hand, suicide behaviors include the spectrum from a death wish to self-harm and completed suicide (4). The rates of self-injurious acts with an apparent death intention, suicide attempts, and total suicides are often used as the best indicators of mental problems in the population due to the difficulty of quantifying other direct indicators of collective psychological distress (5).

From a genetic perspective, parents of children and adolescents who are given up for adoption more frequently meet the criteria for mental disorders, substance use and dependence, and antisocial personality disorders, which means that their children are more vulnerable to meet the criteria for mental disorders (6). Instead, from an environmental perspective, the adoption situation can represent a chronic stressor, and per se produce a negative impact on psychological development (7). This chronic stressor can be called adoption stigma-discrimination, not only of the person in an adoption situation but also of the whole family group (8).

The institutions in charge of processing adoptions in most countries try to ensure that adoptive parents have the best possible characteristics and conditions, with the probable intention of not re-victimizing or causing more significant harm to people who are already in vulnerable circumstances. This situation often delays the adoption 
processes and causes the probability of more considerable emotional damage to occur in minors, which, in turn, can increase the risk of suicide behavior (9). Contrariwise, it should not be forgotten that being in a condition of adoption makes a difference that favors discriminatory treatment by different members of society and creates an adverse environment for the adopted child (10). Something similar to the theory of disability happens here, in the sense that it is the society that constructs the discriminatory condition and the subsequent repercussions on the mental health of adopted children $(10,11)$. In summary, adoptees often present psychiatric morbidity and social disadvantage, and these variables are independent risk factors for suicide attempts among young people $(3,4)$.

Some systematic reviews or meta-analyses have been carried out to summarize the association between the adoption situation and outcomes in intelligence quotient $(9,10)$, cognitive functioning $(12,13)$, social functioning (14), school performance $(15,16)$, behavioral problems (1417), psychological adjustment $(13-15,18)$, and mental health $(14,15,18-21)$. However, no meta-analysis consolidates the information about the specific association between the adoption situation and suicide attempt.

\section{Objectives}

This study aimed to estimate the association between adoption situation and suicide attempts through the systematic review and meta-analysis of observational studies.

\section{Methods}

A meta-analysis of primary studies was done. The review included only studies that compared the outcome of suicide attempts in adopted and non-adopted adolescents and adults.

\subsection{Searching for Relevant Studies}

A logical strategy based on specific descriptors in Spanish, English, and Portuguese was used in combination with the Boolean operators (AND, OR). The search was performed on PubMed, Scopus, Virtual Health Library, ProQuest, EBSCOhost, PsycArticles, BioMed Central, and Sage Journal. The search results in the grey literature were omitted. The descriptors were "adoption", "adopt*", "adopted child", "foster child" "youth in adoption*", "suicide*", "casecontrol study", "case-control", "cohort studies", and "cohort*".

\subsection{Inclusion and Exclusion Criteria}

The authors included articles from January 2000 to December 2018 in English, Portuguese, and Spanish. Searching for meta-analyses solely included papers in Portuguese and Spanish. It also considered case-control and cohort studies on both national and international adoption. We excluded cross-sectional studies and case reports.

\subsection{Data Extraction}

The titles of the studies were initially examined. Subsequently, two authors independently reviewed the abstracts, and finally, the selection of the articles was completed after reading the methods and results sections. The quality of the studies was evaluated with an instrument for critical appraisal of scientific articles (22). This tool adequately summarized the STROBE criteria for observational studies (23).

\subsection{Synthesizing Data and Bias Controlling}

Data synthesis was conducted using RevMan 5 (24). When a primary outcome study reported multiple measures at different points in time, the newest measure was taken because of looking for a long-term consequence. The Odds Ratio (OR) and a 95\% confidence interval (95\% CI) were calculated for case-control studies and the relative risk (RR) and 95\% CI for cohort studies.

\subsection{Assessment of Heterogeneity}

There is a condition for the meta-analysis that the group of trials is sufficiently homogenous in terms of participants and outcomes. The variability among studies is termed heterogeneity, and it can arise from methodological diversity (e.g., age when adopted). Heterogeneity (tau) was evaluated using $\mathrm{I}^{2}$; the values $>50 \%$ were classified as elevated. When heterogeneity is low, the fixed-effects model is indicated; by contrast, the random-effects model is preferred if elevated heterogeneity is observed (25).

\section{Results}

Eight articles met the inclusion criteria. Two papers were excluded due to insufficient information; one allowed the calculation of the association a (3), and the other included the time variable in the analysis without giving details of the number of cases presented (Figure 1) (26).

Of the remaining six studies, three studies used casecontrol designs (27-29) and the remaining three were cohort studies (30-32). Case-control studies computed 69 suicide attempts in 1,216 adopted people compared to 436 attempts among 20,555 non-adopted people ( $\mathrm{OR}=2.30,95 \%$ CI 1.24 - 4.28). A random model was used due to the high 


\begin{tabular}{|c|c|c|c|c|c|c|}
\hline \multirow[t]{2}{*}{ Authors } & \multirow[t]{2}{*}{ Country } & \multicolumn{2}{|c|}{ Adoptees } & \multicolumn{2}{|c|}{ Non-Adoptees } & \multirow[t]{2}{*}{ OR $(95 \% \mathrm{CI})$} \\
\hline & & Events & Total & Events & Total & \\
\hline Slap, 2001 (27) & United States & 15 & 213 & 215 & 6,034 & $1.32(0.62-2.82)$ \\
\hline Fielgeman, $2005(28)$ & United States & 7 & 346 & 212 & 13,743 & $2.15(1.25-3.69)$ \\
\hline Keyes, $2013(29)$ & United States & 47 & 657 & 9 & 508 & $4.27(2.07-8.80)$ \\
\hline
\end{tabular}

${ }^{\mathrm{a}}$ Heterogeneity: $\mathrm{Tau}^{2}=0.18, \mathrm{chi}^{2}=5.14, \mathrm{df}=2, \mathrm{P}=0.08, \mathrm{I}^{2}=61 \%$.

${ }^{b}$ Test of total effect: $Z=2.63, P=0.008$.

${ }^{\mathrm{c}} \mathrm{OR}$ in favor of adoptees: 2.30 (1.24-4.28).

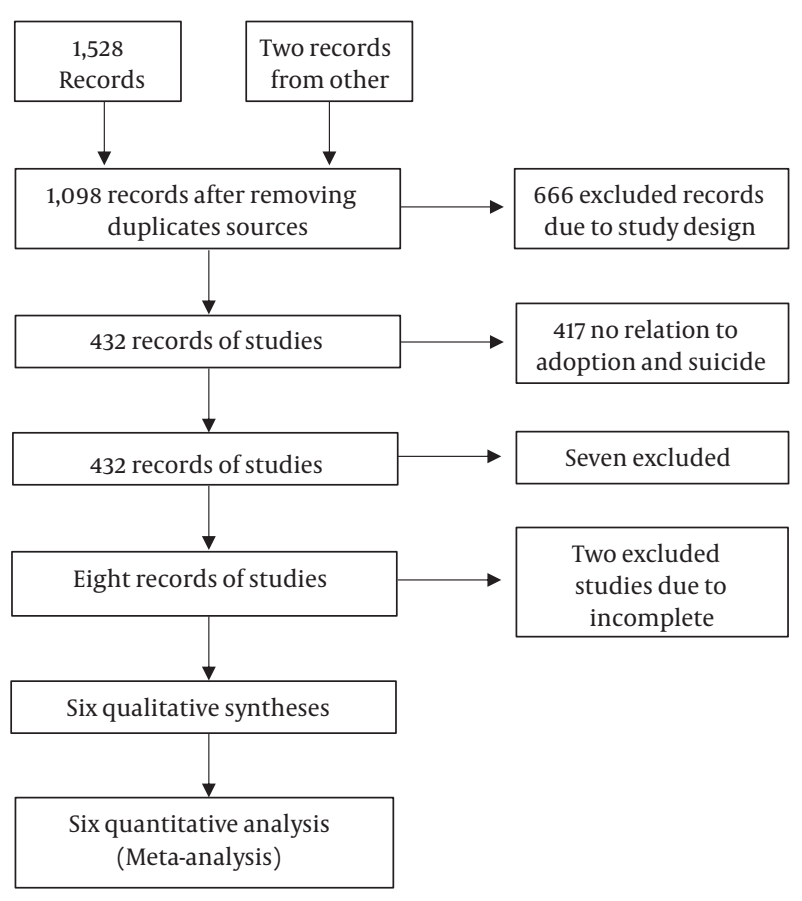

Figure 1. Flow chart of study selection

heterogeneity among the studies $\left(\mathrm{I}^{2}=61 \%\right)$. More details are found in Table 1.

Cohort studies assessed a total of 536 suicide attempts among 36,965 people in adoption compared to 15,112 attempts amidst 3,118,069 non-adopted people $(\mathrm{RR}=2.99$, $95 \% \mathrm{CI} 2.54$ - 3.53). A random model was preferred because of the high heterogeneity $\left(I^{2}=73 \%\right)$. More information is seen in Table 2.

\section{Discussion}

This meta-analysis shows that adopters may have a higher chance of suicide attempts than non-adopters. This observation is consistent with other studies that found that people in adoption had two to three times more risk of total suicide than non-adopted people (33). This finding agrees with other systematic reviews or metaanalyses, which found poorer outcomes for adoptees than persons from the general population on indicators of intelligence quotient, cognitive functioning, social adjustment, school achievement, behavioral troubles, psychological problems, and psychiatric diagnoses (12-21).

The adoption situation is configured as a risk for suicide behaviors because it brings together different factors that increase the possibility of psychological suffering, including behavioral problems, adoption stigmadiscrimination, substance use, and depressive disorders in biological parents (1). Besides, the adoption situation should represent a long-term life stressor with physiological and psychological repercussions that can undermine the general health of adopted people (8).

Moreover, the stigma-discrimination process is an additional negative stressor for adoptees, and it can play a determining role in the negative impact on the mental health of adopted children (8). Being outside the line assumed as "normal" is a starting point that places these children in a condition of vulnerability and adds to the initial vulnerability; the difficulty that people have in understanding and assuming differences is known (3). Alternatively, making an analogy from the theories of disability, institutions, and people builds adverse conditions for adopted children (10, 11). Furthermore, this negative differentiation and these limitations are more decisive, which can cause more considerable damage to the mental health of adopted children and, therefore, increase the risk of suicide attempt (4).

To summarize, the adoption situation brings together disadvantaged cultural, socioeconomic, and biological differences that are all related to suicide behaviors. The high prevalence of psychiatric disorders combined with severe psychosocial circumstances plays an essential role in the frequency of suicide attempts among adoptees $(1,3,4)$. Suicide prevention programs must consider the adoption background as a crucial variable to control $(1,4)$. 


\begin{tabular}{|c|c|c|c|c|c|c|}
\hline \multirow[t]{2}{*}{ Authors } & \multirow[t]{2}{*}{ Country } & \multicolumn{2}{|c|}{ Adoptees } & \multicolumn{2}{|c|}{ Non-Adoptees } & \multirow[t]{2}{*}{$\operatorname{RR}(95 \%$ IC $)$} \\
\hline & & Events & Total & Events & Total & \\
\hline Hjern, 2002 (30) & Sweden & 202 & 11,320 & 4,361 & 853,419 & $3.49(3.04-4.02)$ \\
\hline Vinnerljung et al., 2006 (31) & Sweden & 158 & 12,240 & 4,490 & 995,332 & $2.86(2.44-3.35)$ \\
\hline Von Borczyskowsi et al., 2006 (32) & Sweden & 176 & 13,405 & 6,261 & $1,269,318$ & $2.66(2.29-3.09)$ \\
\hline
\end{tabular}

${ }^{a}$ Heterogeneity: $\mathrm{Tau}^{2}=0.02, \mathrm{chi}^{2}=7.37, \mathrm{df}=2, \mathrm{P}=0.03, \mathrm{I}^{2}=73 \%$.

${ }^{\mathrm{b}}$ Test of total effect: $\mathrm{Z}=13.03, \mathrm{P}<0.0001$

${ }^{c} R R$ in favor of adoptees: 2.99 (2.54-3.53).

\subsection{Strengths and Limitations}

The current meta-analysis suggests a statistically significant relationship between adoption situation and suicide attempts. However, this review has several limitations; it is necessary to interpret the findings with caution since it analyzed observational studies that had more varied populations than randomized clinical trials (34). Also, a small number of investigations were reviewed, and high heterogeneity was observed. Case-control studies were only conducted in the United States and cohort studies exclusively in Sweden. Moreover, the grey literature was excluded $(34,35)$.

In conclusion, the adoption can increase suicide attempts. It predicts at least two times more cases of suicide attempts among adopted people than in the general population. More investigations are needed to deepen the knowledge on this topic. Furthermore, it is necessary to bear in mind the adoption situation when designing programs for the specific prevention of suicide behaviors.

\section{Footnotes}

Authors' Contribution: All authors contributed to the study conception and design, and data interpretation approved the final version and agreed to be accountable for all aspects of the work. J. A. Egurrola-Pedraza and E. Hereazo revised the intellectual content critically. A. CampoArias drafted the article.

Conflict of Interests: The authors have no conflicts of interest.

Funding/Support: The University of Magdalena, Santa Marta, and Human Behavioral Research Institute, Bogota, Colombia, funded the study.

\section{References}

1. Rutter M, Bishop D, Pine D, Scott S, Stevenson J, Taylor E, et al. Rutter's child and adolescent psychiatry. 5th ed. Oxford, Blackwell; 2008.

2. Anthony RE, Paine AL, Shelton KH. Adverse childhood experiences of children adopted from care: The importance of adoptive parental warmth for future child adjustment. Int J Environ Res Public
Health. 2019;16(12). doi: 10.3390/ijerph16122212. [PubMed: 31234480]. [PubMed Central: PMC6617038].

3. Petersen L, Sorensen TI, Andersen PK, Mortensen PB, Hawton K. Genetic and familial environmental effects on suicide-an adoption study of siblings. PLoS One. 2013;8(10). e77973. doi: 10.1371/journal.pone.0077973. [PubMed: 24147105]. [PubMed Central: PMC3798411].

4. Hawton K, van Heeringen K. Suicide. Lancet. 2009;373(9672):1372-81. doi: 10.1016/S0140-6736(09)60372-X. [PubMed: 19376453].

5. Han H, Ahn DH, Song J, Hwang TY, Roh S. Development of mental health indicators in Korea. Psychiatry Inv. 2012;9(4):311-8. doi: 10.4306/pi.2012.9.4.311. [PubMed: 23251193]. [PubMed Central: PMC3521105].

6. Klahr AM, Burt SA, Leve LD, Shaw DS, Ganiban JM, Reiss D, et al. Birth and adoptive parent antisocial behavior and parenting: A study of evocative gene-environment correlation. Child Dev. 2017;88(2):50513. doi: 10.1111/cdev.12619. [PubMed: 27716897]. [PubMed Central: PMC5749403].

7. Darnell FJ, Johansen AB, Tavakoli S, Brugnone N. Adoption and identity experiences among adult transnational adoptees: A qualitative study. Adopt Q. 2016;20(2):155-66. doi: 10.1080/10926755.2016.1217574.

8. Park S, Park KS. Family stigma: A concept analysis. Asian Nurs Res. 2014;8(3):165-71. doi:10.1016/j.anr.2014.02.006.

9. Hillen $T$, Wright $H$. Clinical work with people affected by public care or adoption. BJPsych Adv. 2018;21(4):261-72. doi: 10.1192/apt.bp.108.005702.

10. Park Nelson K. The disability of adoption: Adoptees in disabling societies. Adopt Q. 2018;21(4):288-306. doi: 10.1080/10926755.2018.1526841.

11. Llewellyn A, Hogan K. The use and abuse of models of disability. Disabil Soc. 2000;15(1):157-65. doi:10.1080/09687590025829.

12. van Ijzendoorn MH, Juffer F, Poelhuis CW. Adoption and cognitive development: a meta-analytic comparison of adopted and nonadopted children's IQ and school performance. Psychol Bull. 2005;131(2):301-16. doi: 10.1037/0033-2909.131.2.301. [PubMed:15740423].

13. Fry CE, Langley K, Shelton KH. A systematic review of cognitive functioning among young people who have experienced homelessness, foster care, or poverty. Child Neuropsychol. 2017;23(8):907-34. doi: 10.1080/09297049.2016.1207758. [PubMed: 27584083].

14. Grant M, Rushton A, Simmonds J. Is early experience destiny? Review of research on long-term outcomes following international adoption with special reference to the british chinese adoption study. Sci World J. 2016;2016:6303490. doi: 10.1155/2016/6303490. [PubMed: 27247964]. [PubMed Central: PMC4877486].

15. Christoffersen MN. A study of adopted children, their environment, and development: A systematic review.Adopt Q.2012;15(3):220-37. doi: 10.1080/10926755.2012.700002.

16. Brown A, Waters CS, Shelton KH. A systematic review of the school performance and behavioural and emotional adjustments of children adopted from care. Adopt Foster. 2017;41(4):346-68. doi: $10.1177 / 0308575917731064$. 
17. Bimmel N, Juffer F, van IM, Bakermans-Kranenburg MJ. Problem behavior of internationally adopted adolescents: a review and meta-analysis. Harv Rev Psychiatry. 2003;11(2):64-77. doi: 10.1080/10673220303955. [PubMed: 12868507].

18. Juffer F, van IM. Adoptees do not lack self-esteem: a meta-analysis of studies on self-esteem of transracial, international, and domestic adoptees. Psychol Bull. 2007;133(6):1067-83. doi: 10.1037/00332909.133.6.1067. [PubMed: 17967094].

19. Juffer F, van Ijzendoorn MH. Behavior problems and mental health referrals of international adoptees: a meta-analysis. JAMA. 2005;293(20):2501-15. doi: 10.1001/jama.293.20.2501. [PubMed: 15914751].

20. Behle AE, Pinquart $M$. Psychiatric disorders and treatment in adoptees: A meta-analytic comparison with non-adoptees. Adopt $Q$. 2016;19(4):284-306. doi:10.1080/10926755.2016.1201708.

21. Askeland KG, Hysing M, La Greca AM, Aaro LE, Tell GS, Sivertsen B. Mental health in internationally adopted adolescents: A metaanalysis. J Am Acad Child Adolesc Psychiatry. 2017;56(3):203-213 e1. doi: 10.1016/j.jaac.2016.12.009. [PubMed: 28219486].

22. du Prel JB, Rohrig B, Blettner M. Critical appraisal of scientific articles: part 1 of a series on evaluation of scientific publications. Dtsch Arztebl Int. 2009;106(7):100-5. doi: 10.3238/arztebl.2009.0100. [PubMed: 19562021]. [PubMed Central: PMC2696241].

23. von Elm E, Altman DG, Egger M, Pocock SI, Gotzsche PC, Vandenbroucke JP, et al. The strengthening the reporting of observational studies in epidemiology (STROBE) statement: Guidelines for reporting observational studies. Ann Intern Med. 2007;147(8):573-7. doi: 10.7326/0003-4819-147-8-200710160-00010. [PubMed:17938396].

24. Collaboration C. Review manager (RevMan) version 5.3. The Nordic Cochrane Centre: Copenhagen. 2014.

25. Higgins JP, Thompson SG. Quantifying heterogeneity in a metaanalysis. Stat Med.2002;21(11):1539-58. doi:10.1002/sim.1186. [PubMed: 12111919].

26. Christoffersen MN, Poulsen HD, Nielsen A. Attempted suicide among young people: risk factors in a prospective register based study of
Danish children born in 1966. Acta Psychiatr Scand. 2003;108(5):3508. doi:10.1034/j.1600-0447.2003.00165.x. [PubMed: 14531755].

27. Slap G, Goodman E, Huang B. Adoption as a risk factor for attempted suicide during adolescence. Pediatrics. 2001;108(2). E30. doi: 10.1542/peds.108.2.e30. [PubMed: 11483840].

28. Feigelman W. Are adoptees at increased risk for attempting suicide? Suicide Life Threat Behav. 2005;35(2):206-16. doi: 10.1521/suli.35.2.206.62873. [PubMed: 15843337].

29. Keyes MA, Malone SM, Sharma A, Iacono WG, McGue M. Risk of suicide attempt in adopted and nonadopted offspring. Pediatrics. 2013;132(4):639-46. doi: 10.1542/peds.2012-3251. [PubMed: 24019414]. [PubMed Central: PMC3784288].

30. Hjern A, Lindblad F, Vinnerljung B. Suicide, psychiatric illness, and social maladjustment in intercountry adoptees in Sweden: a cohort study. Lancet. 2002;360(9331):443-8. doi: 10.1016/s01406736(02)09674-5.

31. Vinnerljung B, Hjern A, Lindblad F. Suicide attempts and severe psychiatric morbidity among former child welfare clients-a national cohort study. J Child Psychol Psychiatry. 2006;47(7):723-33. doi: 10.1111/j.1469-7610.2005.01530.x. [PubMed: 16790007].

32. von Borczyskowski A, Hjern A, Lindblad F, Vinnerljung B. Suicidal behaviour in national and international adult adoptees: a Swedish cohort study. Soc Psychiatry Psychiatr Epidemiol. 2006;41(2):95-102. doi: 10.1007/s00127-005-0974-2. [PubMed:16372142].

33. Bettmann JE, Freeman PC, Parry KJ. Differences between adopted and nonadopted adolescents in wilderness and residential treatment. $J$ Exp Educ. 2015;38(3):245-61. doi: 10.1177/1053825915569056.

34. Metelli S, Chaimani A. Challenges in meta-analyses with observational studies. Evid Based Ment Health. 2020;23(2):83-7. doi: 10.1136/ebmental-2019-300129. [PubMed: 32139442].

35. Bero L, Chartres N, Diong J, Fabbri A, Ghersi D, Lam J, et al. The risk of bias in observational studies of exposures (ROBINS-E) tool: concerns arising from application to observational studies of exposures. Syst Rev. 2018;7(1):242. doi: 10.1186/s13643-018-0915-2. [PubMed: 30577874]. [PubMed Central: PMC6302384]. 